Case Report

\title{
Tacrolimus-Induced Type IV Renal Tubular Acidosis following Liver Transplantation
}

\author{
Christopher Schmoyer, ${ }^{1}$ Suraj Mishra, ${ }^{1}$ and Frank Fulco ${ }^{1,2}$ \\ ${ }^{1}$ Department of Internal Medicine, Virginia Commonwealth University, Richmond, VA, USA \\ ${ }^{2}$ Department of Internal Medicine, Hunter Holmes McGuire VA Medical Center, Richmond, VA, USA \\ Correspondence should be addressed to Christopher Schmoyer; christopher.schmoyer@vcuhealth.org
}

Received 15 April 2017; Accepted 1 June 2017; Published 6 July 2017

Academic Editor: Haruki Komatsu

Copyright (C) 2017 Christopher Schmoyer et al. This is an open access article distributed under the Creative Commons Attribution License, which permits unrestricted use, distribution, and reproduction in any medium, provided the original work is properly cited.

\begin{abstract}
Calcineurin inhibitors remain an integral component of immunosuppressive therapy regimens following solid organ transplantation. Although nephrotoxicity associated with these agents is well documented, type IV renal tubular acidosis is a rare and potentially underreported complication following liver transplantation. Hepatologists must be able to recognize this adverse effect as it can lead to fatal hyperkalemia. We describe a case of tacrolimus-induced hyperkalemic type IV renal tubular acidosis in a patient following an orthotopic liver transplant for alcoholic cirrhosis.
\end{abstract}

\section{Introduction}

Calcineurin inhibitors (CNIs) such as cyclosporine and tacrolimus continue to form the backbone of immunosuppressive regimens used in solid organ transplantation [1]. Both acute and chronic nephrotoxicity have been associated with these agents [2]. A case of type IV renal tubular acidosis (RTA), a rare case of acute nephrotoxicity associated with CNI use, is detailed in this report.

\section{Case Report}

A 55-year-old male with a history of decompensated alcoholic cirrhosis and human immunodeficiency virus (HIV) on a fixed dose dolutegravir based regimen (viral load undetectable) underwent an orthotopic liver transplant. Surgery was complicated by intraoperative hypotension resulting in acute tubular necrosis and stage 3 acute kidney injury requiring continuous renal replacement therapy following transplantation. Kidney function returned to baseline by posttransplant day 5 and renal replacement therapy was discontinued. Synthetic function of the liver graft was excellent as noted in laboratory markers of liver failure following transplantation. Aspartate aminotransferase improved from
91 to 20 (15-37 IU/L), alanine aminotransferase from 41 to $72(12-78 \mathrm{IU} / \mathrm{L})$, alkaline phosphatase from 261 to 157 (45-117 IU/L), total bilirubin from 11.8 to $0.4(0.2-1.0 \mathrm{mg} / \mathrm{dL})$, albumin from 1.7 to $3.4(3.4-5.0 \mathrm{~g} / \mathrm{dL})$, and platelets from 31 to $120\left(130-400 \times 10^{3} / \mu \mathrm{L}\right)$ before and after transplant, respectively. There was no clinical, laboratory, or radiologic evidence of graft rejection, biliary stricture, or other complications.

Immediately following transplantation, an immunosuppressive regimen of mycophenolate mofetil and prednisone was initiated. Tacrolimus was added on posttransplant day 5 following resolution of the perioperative acute kidney injury. Serum tacrolimus levels rose thereafter, peaking on posttransplant day 13 at $14.1 \mathrm{ng} / \mathrm{mL}$. During this period, serum potassium levels steadily elevated from a previous normal range, reaching $6.0 \mathrm{mmol} / \mathrm{L}(3.5-5.1 \mathrm{mmol} / \mathrm{L})$ on postoperative day 16. An EKG did not demonstrate prolonged PR or QRS intervals nor peaked $T$ waves. Labs were also notable for elevated chloride of $113 \mathrm{mmol} / \mathrm{L}$ ( $98-107 \mathrm{mmol} / \mathrm{L})$, bicarbonate of $19 \mathrm{mmol} / \mathrm{L}(21-32 \mathrm{mmol} / \mathrm{L})$, and a corrected anion gap of $11.75(8-15 \mathrm{mmol} / \mathrm{L})$. As the patient was not experiencing any diarrhea, a workup for renal causes of his non-anion gap metabolic acidosis was undertaken. Analysis revealed a positive urine anion gap of $53.7 \mathrm{mEq} / \mathrm{L}$. An aldosterone level 
obtained at $8 \mathrm{AM}$ the following morning was suppressed at $2 \mathrm{ng} / \mathrm{dL}(3-16 \mathrm{ng} / \mathrm{dL})$ while renin was inappropriately in the low-normal range at $0.98 \mathrm{ng} / \mathrm{L} / \mathrm{hr}(0.25-5.82 \mathrm{ng} / \mathrm{L} / \mathrm{hr})$. These findings were consistent with type IV renal tubular acidosis. The tacrolimus dose was adjusted to achieve a goal concentration of $10-12 \mathrm{ng} / \mathrm{mL}$. However, serum potassium levels remained elevated. As tacrolimus was an integral part of the immunosuppressive regimen, $0.1 \mathrm{mg}$ fludrocortisone daily was added to correct the patient's hypoaldosterone state. The following day, renal parameters improved to normal range with serum potassium $4.5 \mathrm{mmol} / \mathrm{L}$, chloride $107 \mathrm{mmol} / \mathrm{L}$, and bicarbonate $24 \mathrm{mmol} / \mathrm{L}$. Arterial blood gas was also obtained with $\mathrm{pH} 7.38, \mathrm{pCO}_{2} 48$, and $\mathrm{pO}_{2} 78$. Potassium remained in the normal range throughout the remainder of this hospitalization.

\section{Discussion}

Calcineurin inhibitors exert their immunosuppressive effects by inhibiting nuclear factor of activated T-cells (NFAT) reducing interleukin-2 transcription and T-cell activation [2]. Blocking NFAT mediated gene transcription in other cell types causes many of the adverse effects associated with this drug class. The most common form of CNI nephrotoxicity develops shortly after drug initiation. Activation of the renin-angiotensin system with reductions in nitric oxide, prostaglandin E2, and prostacyclin leads to vasoconstriction of the afferent arteriole. The effect is a dose dependent and reversible elevation in blood pressure and reduction in glomerular filtration rate [3]. Chronic NFAT downregulation leads to hyalinosis of the renal vasculature, tubular atrophy and fibrosis, and glomerular thickening with either segmental or diffuse sclerosis. These changes occurred in the majority of patients on long-term CNI in a cohort following heart transplantation [4].

Type IV RTA is a rare form of acute nephrotoxicity associated with CNI use. This phenomenon has only been described in rare cases following liver transplantation [5-7]. Patients with type IV RTA tend to be asymptomatic with normal creatinine and urine output. However, the associated hyperkalemia can lead to paralysis or fatal arrhythmia making early diagnosis and proper treatment a priority. A high index of suspicion must be maintained for type IV RTA in the presence of normal anion gap metabolic acidosis with associated hyperkalemia and hyperchloremia. The diagnosis is confirmed by abnormal urine studies demonstrating a positive urine anion gap and, often, acidic urine with $\mathrm{pH}$ of $<5.5$. Levels of renin and aldosterone are also frequently low [8]. In general, the cause of type IV RTA is either low levels of aldosterone or the impaired ability of the renal tubule to respond to this hormone. Known etiologies include primary or secondary adrenal insufficiency, acquired or congenital defects in the epithelial sodium channel, and the adverse effects of medications [9]. Common medications linked to type IV RTA include angiotensin inhibitors, potassium sparing diuretics, and trimethoprim [8]. CNIs lead to type IV RTA by reducing the activity of the $\mathrm{Na}^{+} / \mathrm{K}^{+}$ATPase as well as the $\mathrm{Na}^{+} / \mathrm{K}^{+} / 2 \mathrm{CL}^{-}$cotransporter [10]. These changes prevent the kidney from maintaining the normal electrochemical gradient, reducing urinary potassium and hydrogen ion secretion. CNI also downregulates gene expression of mineralocorticoid receptors which, through a still unknown mechanism, leads to reductions in serum aldosterone itself [11]. The hyperkalemia associated with CNI induced type IV RTA may improve with dose reductions of the immunosuppressive agent. However, treatment of the underlying hypoaldosterone state with a mineralocorticoid, such as fludrocortisone, is often required $[12,13]$. In conclusion, type IV RTA is a rare and underreported complication of tacrolimus use following liver transplantation that must be recognized by hepatologists as it can lead to severe and potentially fatal hyperkalemia.

\section{Conflicts of Interest}

The authors declare there are no conflicts of interest regarding the publication of this paper.

\section{References}

[1] M. R. Lucey, N. Terrault, L. Ojo et al., "Long-term management of the successful adult liver transplant: 2012 practice guideline by the American Association for the Study of Liver Diseases and the American Society of Transplantation," Liver Transplantation, vol. 19, no. 1, pp. 3-26, 2013.

[2] N. Issa, A. Kukla, and H. N. Ibrahim, "Calcineurin inhibitor nephrotoxicity: a review and perspective of the evidence," American Journal of Nephrology, vol. 37, no. 6, pp. 602-612, 2013.

[3] P. Malvezzi and L. Rostaing, "The safety of calcineurin inhibitors for kidney-transplant patients," Expert Opinion on Drug Safety, vol. 14, no. 10, pp. 1531-1546, 2015.

[4] B. D. Myers, J. Ross, L. Newton, J. Luetscher, and M. Perlroth, "Cyclosporine-associated chronic nephropathy," New England Journal of Medicine, vol. 311, no. 11, pp. 699-705, 1984.

[5] M. Riveiro-Barciela, I. Campos-Varela, J. L. Tovar et al., "Hyperkalemic distal renal tubular acidosis caused by immunosuppressant treatment with tacrolimus in a liver transplant patient: Case report," Transplantation Proceedings, vol. 43, no. 10, pp. 40164018, 2011.

[6] K. Ogita, N. Takada, T. Taguchi et al., "Renal Tubular Acidosis Secondary to FK506 in Living Donor Liver Transplantation: A Case Report," Asian Journal of Surgery, vol. 26, no. 4, pp. 218220, 2003.

[7] W. Lin, L. Mou, H. Tu et al., "Clinical analysis of hyperkalemic renal tubular acidosis caused by calcineurin inhibitors in solid organ transplant recipients," Journal of Clinical Pharmacy and Therapeutics, vol. 42, no. 1, pp. 122-124, 2017.

[8] J. Yaxley and C. Pirrone, "Review of the diagnostic evaluation of renal tubular acidosis," Ochsner Journal, vol. 16, no. 4, pp. 525530, 2016.

[9] F. E. Karet, "Mechanisms in hyperkalemic renal tubular acidosis," Journal of the American Society of Nephrology, vol. 20, no. 2, pp. 251-254, 2009.

[10] S. Aker, P. Heering, E. Kinne-Saffran et al., "Different effects of cyclosporine A and FK506 on potassium transport systems in MDCK cells," Experimental Nephrology, vol. 9, no. 5, pp. 332340, 2001.

[11] P. J. Heering, C. Kurschat, D. T. Vo, N. Klein-Vehne, K. Fehsel, and $\mathrm{K}$. Ivens, "Aldosterone resistance in kidney transplantation is in part induced by a down-regulation of mineralocorticoid 
receptor expression," Clinical Transplantation, vol. 18, no. 2, pp. 186-192, 2004.

[12] J. McCauley, J. J. Fung, S. Todo et al., "Changes in renal function after liver transplantation under FK 506," Transplantation Proceedings, vol. 23, no. 6, pp. 3143-3145, 1991.

[13] V. Sivakumar, P. Sriramnaveen, C. Krishna et al., "Role of fludrocortisone in the management of tacrolimus-induced hyperkalemia in a renal transplant recipient.," Saudi journal of kidney diseases and transplantation: an official publication of the Saudi Center for Organ Transplantation, Saudi Arabia, vol. 25, no. 1, pp. 149-151, 2014. 


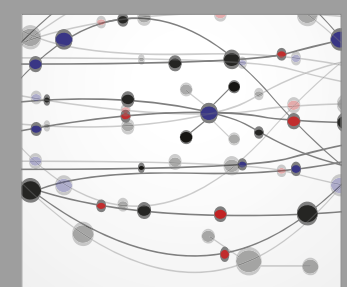

The Scientific World Journal
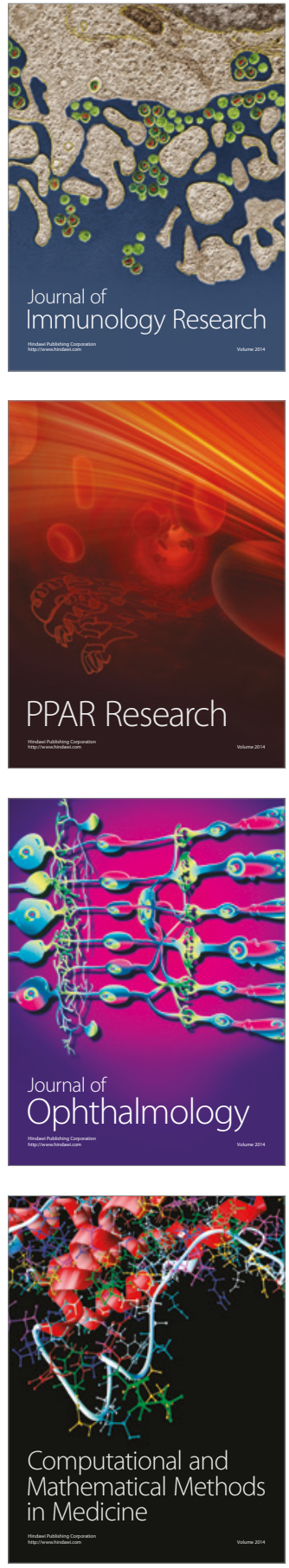

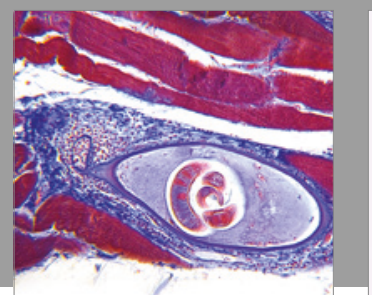

Gastroenterology Research and Practice
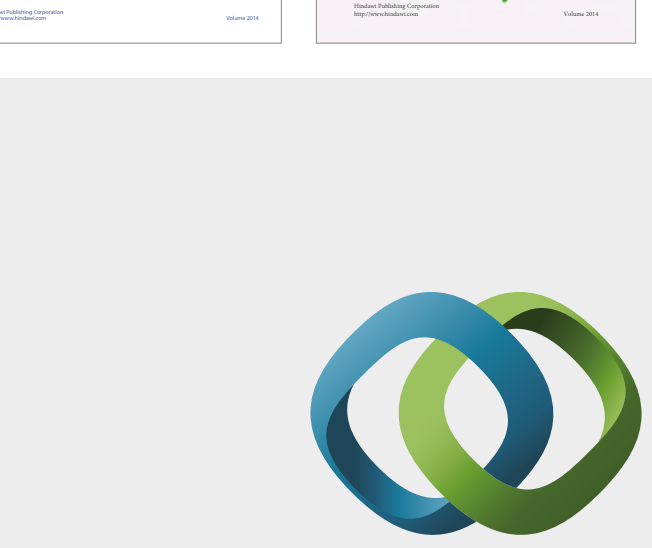

\section{Hindawi}

Submit your manuscripts at

https://www.hindawi.com
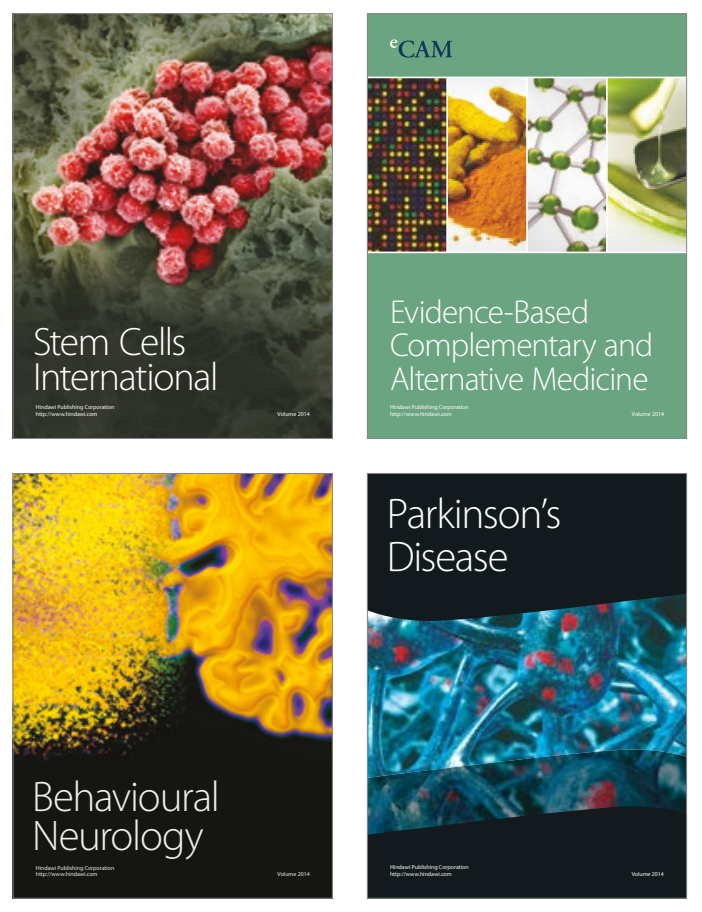
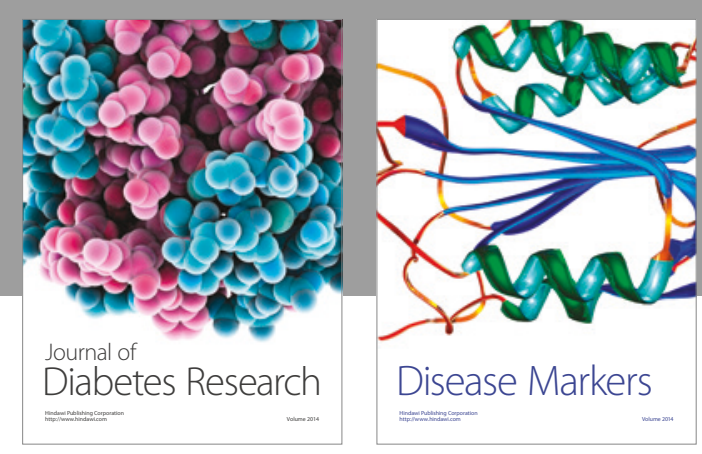

Disease Markers
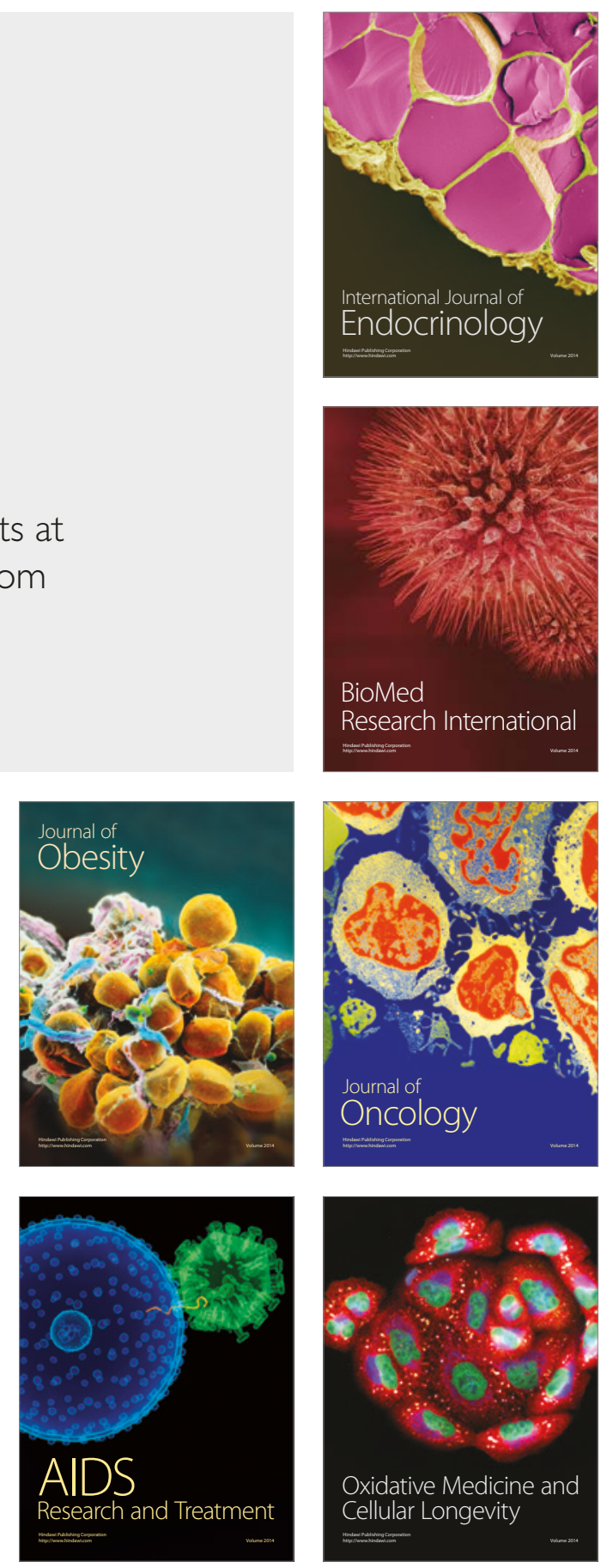